\title{
O bem-estar dos usuários nos ambientes construídos: Uma revisão de literatura através da Psicologia Ambiental e da Ergonomia.
}

\author{
User welfare in built environments: A literature review through \\ Environmental Psychology and Ergonomics.
}

\begin{abstract}
CIBELE DE OLIVEIRA PARREIRAS GOMES
Mestranda, Universidade de Fortaleza/Centro Universitário Estácio, cibele@cibeleparreiras.arq.br
\end{abstract}

ADRIANA CASTELO BRANCO PONTE DE ARAÚJO

Mestranda, Universidade Federal do Ceará/ Instituto Federal de Educação, Ciência e Tecnologia do Ceará, acbranco2003@yahoo.com.br

CAMILA BANDEIRA PINHEIRO LANDIM

Doutoranda, Universidade de Lisboa/Universidade de Fortaleza, camila.bandeira@unifor.br

\section{RESUMO}

Os conceitos da Psicologia Ambiental presentes nos ambientes construídos tornam-se determinantes para o aumento do bem-estar dos indivíduos frequentadores desses espaços, buscando compreender as razões das diferentes sensações provocadas. As experiências contemplativas e de interação pessoaambiente, na sociedade contemporânea, apresentam-se como um bem necessário para o encontro da felicidade e melhoria da qualidade de vida. Essas vivências resultam na apropriação positiva desses espaços, que transformam-se em lugares repletos de significados. Para tanto, foi conduzida uma pesquisa bibliográfica, por meio de uma revisão de literatura em base de dados científicos, buscando evidenciar elementos da Psicologia Ambiental e da Ergonomia existentes nos espaços projetados, destacando as influências dessas disciplinas nos projetos de ambientes residenciais, corporativos e educacionais. Os profissionais de arquitetura e design são agentes essenciais, viabilizando a qualidade física dos espaços, seja nas escalas de microambiente, de espaços partilhados semipúblicos ou ambientes coletivos públicos, que possuem grande potencial para tornarem-se ambientes restauradores. Esta pesquisa mostrou-se relevante na medida em que demonstrou um panorama apresentado por diversos autores sobre a necessidade das interrelações pessoa-ambiente e a possibilidade de vivenciá-las com mais facilidade nos ambientes projetados com base em conceitos da Psicologia Ambiental e Ergonomia.

PALAVRAS-CHAVE: ambientes construídos, psicologia ambiental, bem-estar, ergonomia.

\section{ABSTRACT}

The concepts of Environmental Psychology present in the built environments become decisive for increasing the well-being of individuals who frequent these spaces, seeking to understand the reasons 


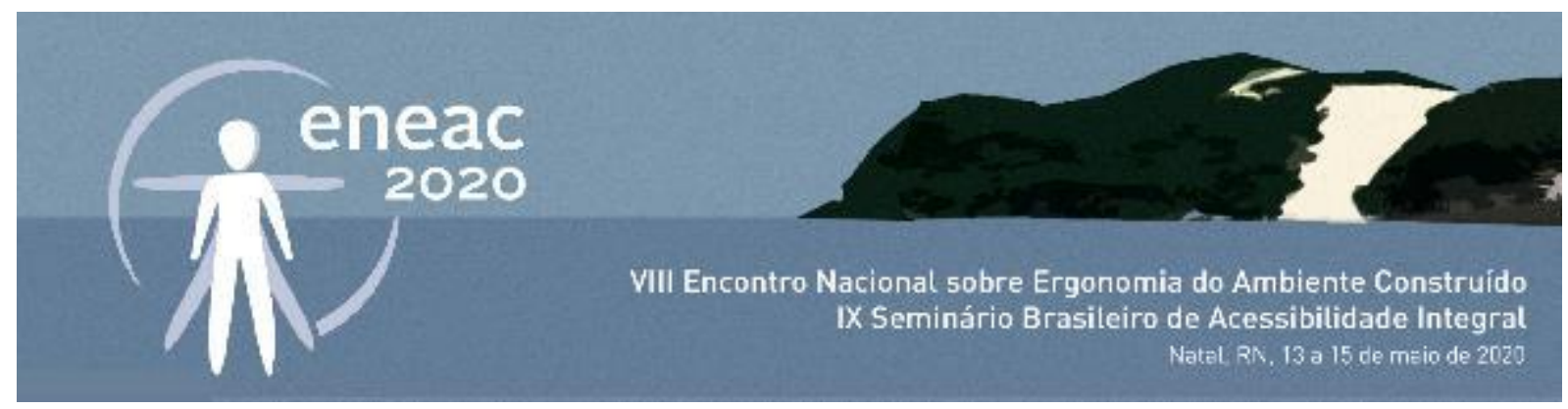

for the different sensations caused. The contemplative and person-environment interaction experiences, in contemporary society, present themselves as a necessary asset for finding happiness and improving the quality of life. These experiences result in the positive appropriation of these spaces, which become places full of meanings. To this end, a bibliographic research was conducted, through a literature review in scientific databases, seeking to highlight elements of Environmental Psychology and Ergonomics existing in the projected spaces, highlighting the influences of these disciplines in the projects of residential, corporate and educational environments. . Architecture and design professionals are essential agents, enabling the physical quality of spaces, whether in micro-environment scales, semi-public shared spaces or public collective environments, which have great potential to become restorative environments. This research proved to be relevant insofar as it demonstrated a panorama presented by several authors on the need for person-environment interrelationships and the possibility of experiencing them more easily in environments designed based on concepts from Environmental Psychology and Ergonomics.

KEYWORDS: built environments, environmental psychology, wellness, ergonomics.

\section{INTRODUÇÃO}

Um ambiente, seja interno ou externo, de acordo com os conceitos da Psicologia Ambiental, influencia as pessoas que o frequentam, como também é influenciado por elas. É nesse contexto que procurou-se perpassar por diversos estudos e conceitos das relações pessoa-ambiente, para que, relacionando-os com os ambientes construídos, possa-se mostrar a importância destes para o bemestar dos seus usuários.

Para tanto, neste estudo, optou-se por uma revisão narrativa de literatura, buscando-se evidenciar elementos da Psicologia Ambiental e da Ergonomia existentes nos espaços projetados, destacando as influências dessas disciplinas nos projetos de ambientes residenciais, corporativos e educacionais.

Entende-se por um bom projeto arquitetônico aquele que não só satisfaz as necessidades do cliente, mas também é capaz de tornar os seus anseios em realidade. Um ambiente construído quando é planejado por um profissional de arquitetura, respeitando a normatização exigida pela legislação e exigências da Ergonomia, além dos conceitos da Psicologia Ambiental, tem amplas possibilidades de alcançar o bem-estar tão almejado por seus respectivos usuários. A Ergonomia pode ser conceituada como o conjunto de disciplinas que estuda a organização do trabalho no qual existem interações entre seres humanos e as máquinas, dentro de um determinado ambiente.

A ergonomia é a forma de adaptarmos o trabalho ao homem, auxiliando no conforto e no bem-estar das atividades. Esse bem-estar está associado a tudo que faz parte do ambiente, como:

equipamentos, objetos, mobiliários, ventilação e iluminação adequada para determinado tipo de serviço. Pensarmos em ergonomia é pensarmos em diminuição de acidentes, aumento da qualidade de vida e da produtividade, redução de custos, ou seja, a eficiência é uma consequência da aplicação ergonômica no ambiente de trabalho. (IIDA, 2005).

Kuhn e Barbosa (2016), afirmam que o principal objetivo da ergonomia, de acordo com Organização Internacional do Trabalho, é a junção das áreas de ciências humanas com as técnicas da engenharia, de forma a atingir o ponto de equilíbrio entre o bem-estar do homem e sua eficiência no ambiente de trabalho. Outra consideração importante, na qual a ergonomia pode contribuir para o bem-estar 


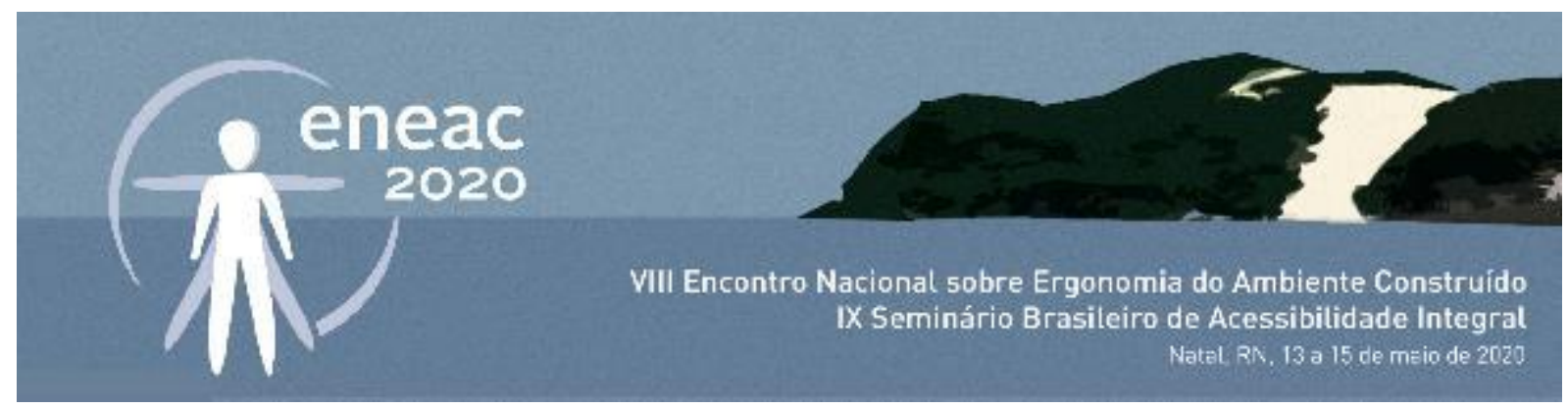

psíquico do trabalhador, é o fato dela estar associada aos aspectos emocionais do ser humano, não se restringindo apenas às questões fisiológicas e cognitivas do mesmo.

Podemos observar, assim, a importância de alguns conceitos da Psicologia Ambiental na relação pessoa-ambiente de uma maneira geral, onde estes ambientes, inevitavelmente, estabelecem relações com as pessoas que os frequentam, adquirindo sentido e maior relevância de acordo com as experiências vividas, tornando-os especiais para seus usuários que manifestam de diversas maneiras seus afetos em relação a esses espaços, transformando-os em lugares que se enchem de significado (CAVALCANTE; NÓBREGA, 2011; KUHNEN, 2001); Lugares estes que passam a ter extrema importância para essas pessoas, por guardarem memórias de momentos importantes de suas vidas, por serem palco de experiências únicas ou simplesmente por fazerem parte de seu cotidiano, como uma pessoa com quem convive-se todos os dias, acostumando-se com sua companhia.

A Psicologia Ambiental relaciona os aspectos físicos dos ambientes com a percepção, a atitude, o sentimento e o comportamento de seus usuários, inserindo-os, também, no contexto social, econômico, político e cultural da sociedade. (CARVALHO; CAVALCANTE; NÓBREGA, 2011). Assim, o ambiente engloba uma variedade de elementos, não se limitando apenas aos aspectos físicos, e o ambiente projetado, além de todos esses pontos, incorpora, ainda, aspectos funcionais, estéticos, ergonômicos, qualitativos, visando proporcionar maior sensação de conforto, agradabilidade, bemestar e uma maior qualidade de vida para aqueles que o usufruem.

Furtado (2005, apud FALAVIGNA; BAVARESCO,2018) reforça que a Psicologia Ambiental pode ser considerada uma psicologia do espaço, pois ela observa os comportamentos e percepções das pessoas em suas relações com o ambiente físico e social no qual se desenvolve. A relação indivíduoambiente é analisada em quatro níveis de referência espacial e social: o microambiente - o espaço privado, a moradia, implicando o indivíduo; os ambientes de proximidade - os espaços partilhados semipúblicos, o habitat coletivo, o bairro, o lugar de trabalho, os parques e os espaços verdes, concernentes à comunidade de proximidade ou de vizinhança; os ambientes coletivos públicos - as cidades, os vilarejos, e os povoamentos diversos, implicando os agregados de indivíduos; e o ambientes global - o ambiente em sua totalidade, construído ou não, os recursos naturais e os concernente à sociedade enquanto tal.

Dessa forma, percebem-se, na Psicologia Ambiental, diversos elementos que facilitam a compreensão completa do espaço projetado, público ou privado, e seus usos, como aspectos afetivos, cognitivos e subjetivos, levando os indivíduos a uma maior interação, além de experimentarem de maneira mais profunda o ambiente no qual vivenciam o cotidiano (BERTINI, 2006).

O ambiente influencia as pessoas que o utilizam, da mesma forma em que é influenciado por elas, pelas suas ações e atitudes, fazendo, assim, parte de seu cotidiano e ocupando um papel importante na escrita de suas histórias de vida, pois nos principais momentos vividos, sendo estes positivos ou negativos, o ambiente tem presença marcante, ficando guardado na memória, muitas vezes, juntamente com o cheiro, a temperatura, os ruídos, a presença de pessoas e muitos outros elementos que juntos retratam de maneira global determinado espaço. Estes estímulos provocam sensações diferentes em cada indivíduo, onde as reações dependem da forma que estão sendo transmitidas, somadas a personalidade de cada pessoa, além dos aspectos culturais, sociais ou emocionais, que se consolidam em uma experiência sensorial única e exclusiva para cada indivíduo. 


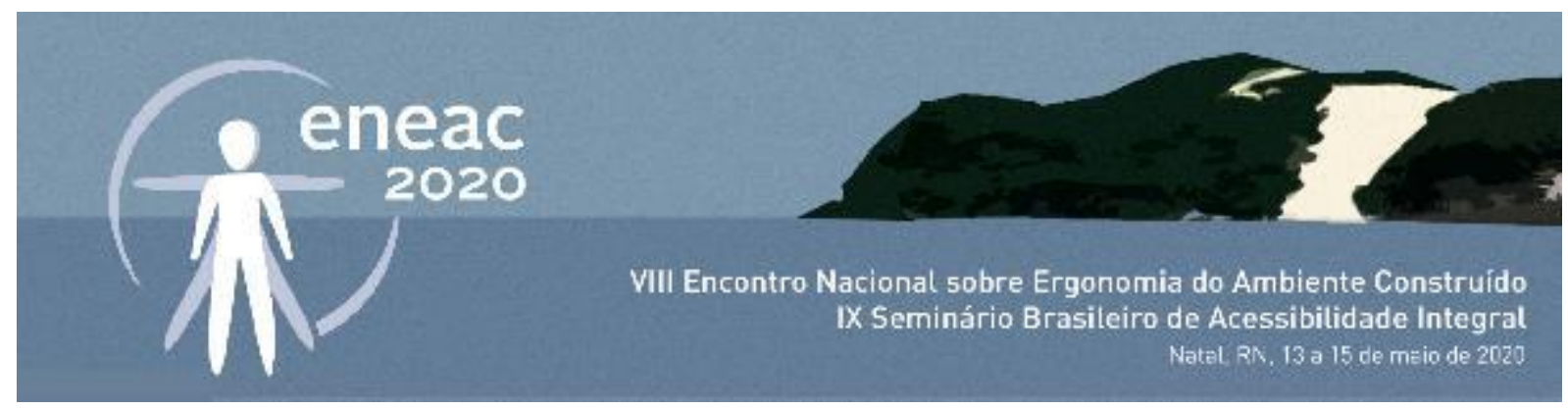

Assim, é de suma importância identificar-se os diversos elementos da Psicologia Ambiental presentes nos ambientes construídos, destacando as diversas relações pessoa-ambiente ocorridas nesses espaços, que além de facilitarem essas experiências, podem atuar, também, como fortalecedoras das relações interpessoais.

\section{METODOLOGIA}

Neste estudo, optou-se por uma revisão sistemática de literatura que tem como objetivo resumir as informações existentes sobre o tema em questão, de maneira imparcial e completa. Assim, foram selecionados artigos e livros sobre ergonomia e psicologia ambiental, consultados em bases de dados com relevância científica. Após análise do material encontrado, optou-se pelas obras dos autores com maior destaque em cada área.

Através dessa revisão sistemática, buscou-se contribuir para um maior conhecimento na área, verificando a necessidade de abordar essa temática subdividida em diferentes categorias como: residencial, corporativa e educacional, destacando a importância desses espaços como ambientes restauradores dos usuários.

\section{A PSICOLOGIA AMBIENTAL E O CONCEITO DE AMBIENTES RESTAURADORES NOS ESPAÇOS CONSTRUÍDOS}

A identificação e o bem-estar do usuário dentro dos ambientes construídos está diretamente relacionada às diversas escalas e tipologias espaciais, assim como devem ser consideradas a pluralidade de culturas e etnias que existem nas sociedades. O comportamento e as ações dos indivíduos nos espaços projetados podem ser estudados tanto nos espaços livres da cidade como nos ambientes internos, onde a qualidade destes estimula a permanência das pessoas, propiciando vivências que contribuem para o bem-estar das mesmas. Quando, por exemplo, os espaços públicos são mais acessíveis aos pedestres, certamente sua frequência nestes espaços aumenta, levando, assim, os indivíduos a movimentarem-se mais, exercitando-se e, consequentemente, sentindo-se melhor (MOLAVI; SEYEDABADI; ZALI, 2017), o que acarreta, com o tempo, uma melhoria, também, da saúde coletiva.

Ambiente, para a Psicologia Ambiental, é um conceito amplo, englobando tanto o espaço físico, construído, como os aspectos psicológicos, sociais, econômicos e culturais do contexto específico. (CARVALHO; CAVALCANTE; NÓBREGA, 2011). Dessa forma, é importante que se apresentem alguns conceitos da Psicologia Ambiental presentes nas relações existentes entre as pessoas e os ambientes, tendo em vista a identificação destes nos ambientes construídos e sua relação com seus usuários, bem como sua importância para a melhoria da saúde psíquica dos indivíduos que os frequentam.

A Psicologia Ambiental é dedicada ao estudo das relações pessoa-ambiente, englobando tanto processos afetivos como cognitivos, perpassando pelos sentimentos, pelos pensamentos e pelas 


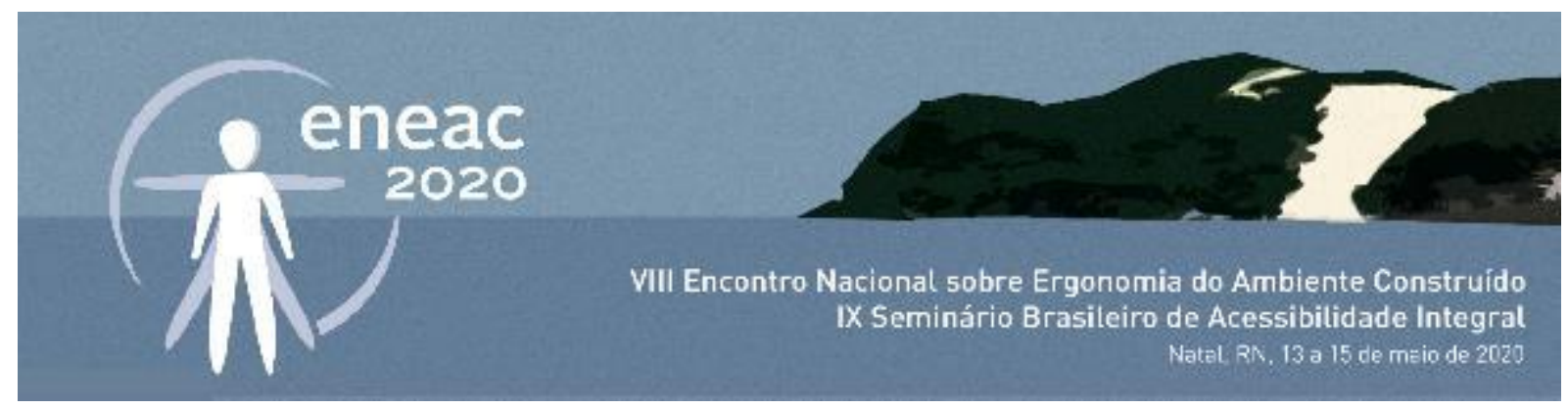

vivências nos espaços onde as pessoas estão inseridas e consolidando, assim, diversos conceitos, como o de sentimento de comunidade, apego ao lugar, apropriação e identidade de lugar (LIMA; BOMFIM, 2009). Esses conceitos atuam, cada um de uma maneira diferente, com intensidades e características distintas, na vida das pessoas que usufruem desses espaços.

O sentimento de comunidade é considerado um afeto das pessoas com a comunidade onde moram, fazendo aflorar sentimentos de satisfação além da vinculação com este local, enquanto que o apego ao lugar diz respeito a diversos tipos de ambientes, entre eles, também, a própria comunidade, estando ligado às vivências do dia a dia que ligam as pessoas a determinado lugar, criando vínculos com ele e identificando-se com o mesmo, tornando mais difícil o apego a outros tipos de lugares. (LIMA; BOMFIM, 2009; KUHNEN, 2001)

É comum que todos já tenham experimentado sentimentos de apego a determinados lugares, sobretudo àqueles com os quais foram criados laços afetivos, podendo ser em pequena ou grande escala, como alguns locais frequentados na infância ou locais sonhados para o futuro, sendo esses laços de grande importância para a qualificação da existência dos indivíduos, de maneira positiva ou negativa. (GIULIANI, 2004)

Segundo Moser (2018), a relação da pessoa com o ambiente pode se dar pela experiência individual com vários tipos de espaços, como uma casa da infância, o habitar mítico ou o ambiente cotidiano, sendo três os termos que expressam as relações do indivíduo com seu ambiente próximo: a apropriação, a ligação e o enraizamento. A apropriação consiste nas relações cognitivas e afetivas entre a pessoa e um determinado lugar, já a ligação consiste em um espaço de ancoragem, de referência, com o qual a pessoa estabelece forte ligação, deixando os demais espaços como um prolongamento desse ponto central. O enraizamento, por sua vez, está baseado no sentimento de pertença e na conexão adquirida com o lugar.

Esses sentimentos presentes nas relações pessoa-ambiente perpassam a história do lugar e as interações críticas e afetivas, sendo o indivíduo responsável pela construção do espaço, enquanto é, também, construído por ele, tornando-o um ambiente mais saudável, agradável, seguro e acessível. (SIEBRA et al., 2015) Nota-se, nesse contexto, que a intensidade desses sentimentos varia de acordo com a vinculação existente entre o sujeito e o ambiente, sendo mais intensos os sentimentos presentes naqueles indivíduos que possuem maior vínculo com o ambiente, como é o caso, por exemplo, das pessoas idosas em relação às casas nas quais viveram a vida inteira, com seus filhos e netos.

Outro elemento da Psicologia Ambiental de extrema importância nos ambientes construídos é o conforto, estando este presente de maneira mais perceptível nas habitações e nos locais de trabalho. O conforto pode ser relacionado ao sentimento, à percepção, ao humor e à situação, tendo sido muito pouco explorado, apesar de estar associado à qualidade de vida e de bem-estar. Pode-se distinguir dois tipos de conforto: o sensorial, ligado aos sentidos, e o existencial, ligado às qualidades ambientais voltadas para o plano psíquico (MOSER, 2018).

O conforto é, portanto, definido como qualidade que é experimentada pelos usuários, não sendo suficiente atender apenas às exigências funcionais, mas também às psicológicas dos mesmos, podendo ser considerado como um indicador da relação pessoa-ambiente (MOSER, 2018), já que proporciona experiências bastante abrangentes com os espaços, sobretudo os projetados, por possuírem maior preocupação com o alcance dessa sensação, possibilitando, assim, o aumento da 


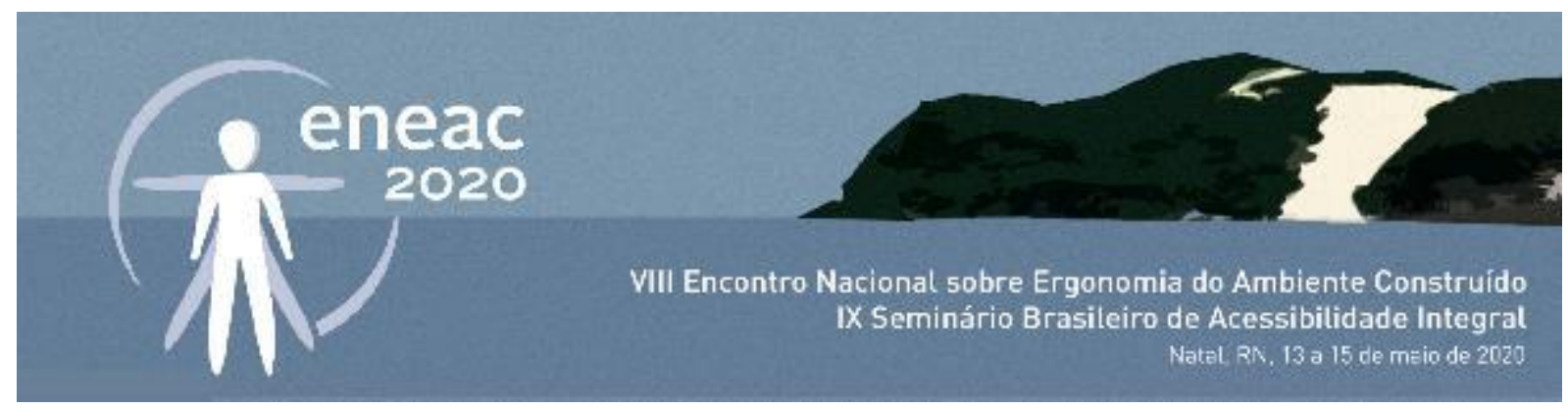

qualidade de vida daqueles que usufruem desses ambientes.

As pessoas adquirem vínculos com determinados espaços que, ao se tornarem lugares, passam a ter importante papel em suas vidas. $O$ espaço transformado em lugar passa a adquirir características mais subjetivas, sem limites físicos, sendo relacionado aos sentimentos e às experiências vivenciadas nele (CAVALCANTE; NÓBREGA, 2011; LIMA; BOMFIM, 2009).

O espaço está relacionado aos aspectos físicos, construídos, enquanto o lugar é repleto de significados, ligados aos aspectos subjetivos. O lugar tem um sentido essencial para o indivíduo, tornando-se, muitas vezes, através da apropriação, extensão da subjetividade destes e é de extrema importância no processo de evolução da espécie, como também nos processos das transformações sociais (BOMFIM et al., 2018; FELIPPE; KUHNEN, 2012). De acordo com Gifford (2014), o lugar possui significados simbólicos onde suas características físicas podem contribuir para a sua construção, podendo a perda de determinado lugar ser algo tão doloroso quanto a perda de um ente querido.

Independente do contato físico, o lugar é real na memória e nas lembranças das pessoas, tornandose símbolo e fazendo aflorar a vontade de experimentá-lo, surgindo, nesse contexto, sentimentos de apego, conforto e segurança, além dos de apropriação, conectando-se com memórias históricas e culturais (LIMA; BONFIM, 2009; PONTE; BOMFIM; PASCUAL, 2009). Percebe-se, nesse contexto, o quanto o ambiente é importante na vida das pessoas, mesmo que não seja percebido por estas, ficando guardado, para sempre, nas lembranças e sentimentos vivenciados no local, independentes de serem estes positivos ou negativos, eles se encarregam de resgatar as relações ocorridas entre as pessoas e o ambiente.

Ainda segundo Lima e Bomfim (2009), o apego encontra dificuldade de se estabelecer devido à padronização dos ambientes, tornando-os rígidos e impessoais e, portanto, mais difíceis de estimularem esse tipo de sentimento, devido à dificuldade de vinculação dos indivíduos com os espaços. No caso dos ambientes planejados de forma personalizada, o conceito de apego aflora com maior facilidade, aumentando a interação entre os indivíduos e os espaços.

Nesse contexto, surge a identidade de lugar, fruto da significação dos lugares juntamente com o sentimento de apropriação dos mesmos (LIMA; BOMFIM, 2009; PONTE; BOMFIM; PASCUAL, 2009), no qual o conceito de apropriação está calcado no processo de inter-relação pessoa-ambiente e na transformação de ambos. (FRANCISCO et al., 2014; MORAIS; ARAÚJO; BARBOSA; ABREU; SIEBRA, 2011)

A identidade de lugar nasce de experiências com o ambiente físico, no qual o indivíduo tem uma identificação com o lugar, de onde nascem referenciais simbólicos e afetivos, que abrangem elementos como: memórias, pensamentos, valores, preferências, senso de comunidade, dependência de lugar e identidade ambiental (KUHNEN, 2001; GIFFORD, 2014; PONTE et al., 2009).

Outro elemento que aparece frequentemente nos estudos sobre o assunto abordado é a ambiência, que pode se apresentar de várias formas, variando de acordo com o público que vivencia o ambiente. No processo de compreensão da relação entre elementos psicológicos e ambientais, é importante, na análise do espaço físico, a observação dos aspectos sociais e funcionais, englobando tanto os símbolos quanto a influência nas ações das pessoas. Para Elali (2009), a ambiência abrange todas as sensações do espaço, podendo ser visíveis ou invisíveis, sendo estas percebidas, sentidas e interpretadas de forma distinta por cada pessoa. 


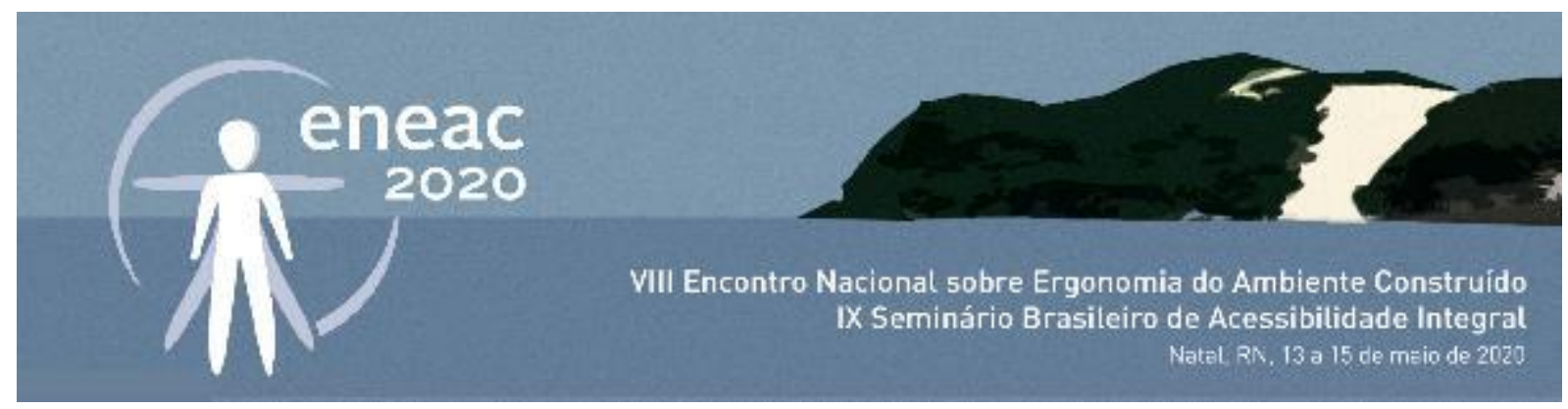

Segundo Thibaud (2018), a ambiência é composta por um conjunto de experiências, das quais diversos fatores se integram e levam as pessoas a interiorizá-los, de forma que as atividades desenvolvidas no ambiente podem tomar rumos e resultados diferentes. Assim, percebe-se que os ambientes projetados podem proporcionar o surgimento de diversas ambiências, fazendo com que os usuários experimentem de maneira singular essas sensações que contribuem para o maior bemestar dos indivíduos.

Os ambientes projetados acabam resgatando vários aspectos das experiências das pessoas, como os históricos, os afetivos e o de apropriação, sendo esses espaços compostos por elementos sensoriais, simbólicos, físicos e materiais, fazendo com que seus usuários criem vínculos com esses locais (LEITE, 2010). Nesse contexto, outro aspecto importante é quando um ambiente atua na restauração física e/ou psíquica dos indivíduos, sendo considerado um ambiente restaurador, o qual é composto por diversos elementos que atuam nesse papel, como plantas, materiais naturais, iluminação quente, elementos da natureza (água, pedras, madeira).

A Ergonomia, nesse contexto, também pode atuar como parceira da Psicologia Ambiental na concepção de projetos mais eficientes e confortáveis, sendo, portanto, de suma importância a aplicação de seus conceitos nos espaços projetados.

Como pode-se observar, diversos conceitos da Psicologia Ambiental estão presentes nas relações pessoa-ambiente nos espaços, tanto privados, quanto públicos, e de maneira especial nos projetados, que juntamente com aspectos ergonômicos, visam proporcionar maior conforto e aconchego aos seus frequentadores, objetivando a melhoria da qualidade de vida.

O conceito de ambientes restauradores também é abordado pela Psicologia Ambiental nos últimos anos e bastante utilizado nos projetos urbanísticos, arquitetônicos e de design de interiores contemporâneos. As características mais marcantes desses ambientes são a presença de elementos da natureza, como plantas, água; o uso de materiais naturais como a madeira, a pedra, as tramas, entre outros que remetam à natureza, trazendo sensações agradáveis e restauradoras para as pessoas que os frequentam.

Os ambientes com a presença de elementos naturais protegem as pessoas do estresse, além de promoverem maior restauração fisiológica e emocional do que os espaços construídos, atuando como verdadeiros ambientes restauradores, os quais têm efeitos positivos tanto no âmbito físico quanto cognitivo do indivíduo. As pessoas, em geral, preferem os ambientes com características naturais porque esses espaços intensificam o bem-estar psicofisiológico humano (BERTO, 2014).

Praças e parques são exemplos de espaços públicos com grande potencial para serem ambientes restauradores, pois reúnem a presença da natureza (vegetação, água, animais, etc.) com estruturas construídas que promovem o lazer e estimulam a contemplação. No Parque Inhotim, localizado em Brumadinho (MG) foi idealizada a proposta de um parque-museu, com um refinado projeto paisagístico, onde a presença de obras de arte a céu aberto associada a elementos naturais propiciam um cenário de agradável permanência (ver figura 4). 

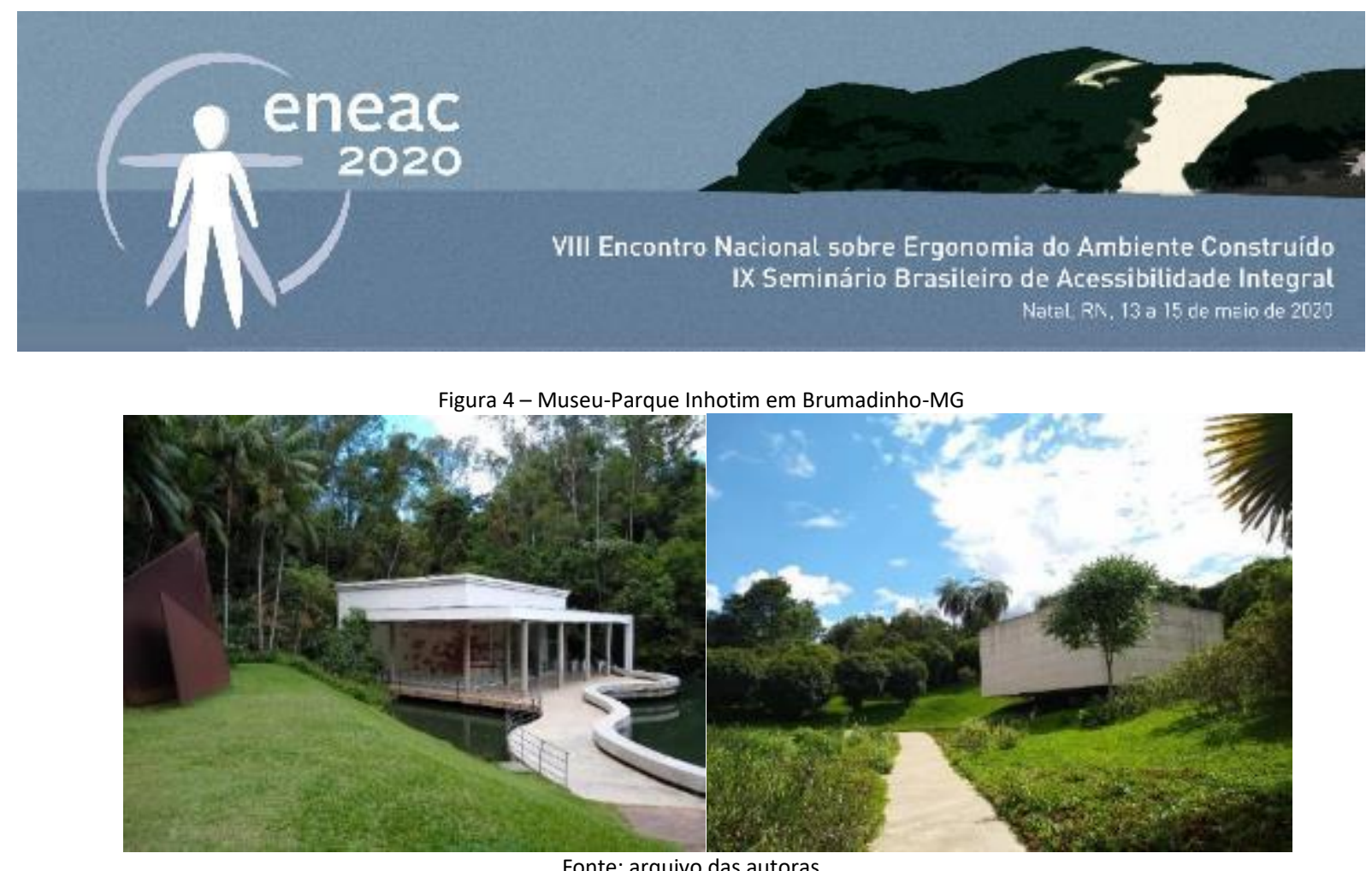

Fonte: arquivo das autoras

A contemplação da natureza nos ambientes projetados e construídos leva as pessoas a experiências interiores de paz e tranquilidade. Tais locais são ambientes de restauração tanto física quanto psíquica, ocupando um importante papel na vida daqueles que os frequentam, estimulando o encontro com a natureza, com o outro e consigo mesmos (RAIMUNDO; SARTI, 2016), além de gerarem sensações de agradabilidade e conforto, propiciando o aumento do bem-estar.

Dessa forma, tem-se percebido uma valorização e procura cada vez maior por espaços com elementos restauradores, reconhecendo-se seus benefícios para aqueles que frequentam, utilizam ou habitam esses espaços, de maneira a criarem vínculos e sentimentos afetivos para com os mesmos, além, de melhoria da saúde física e psíquica dessas pessoas.

\subsection{A Psicologia Ambiental e Ergonomia nos Espaços Residenciais}

A aplicação da Psicologia Ambiental nos projetos residenciais também tem grande relevância na qualidade de vida dos seus respectivos usuários. Esse conceito baseia-se, pois, nas dimensões afetivas e temporais da experiência ambiental, constituindo a relação pessoa-ambiente, sendo os fatores de grande relevância: a duração da residência e a sensação de tranquilidade da vizinhança. Alguns autores concluem, portanto, que uma boa relação de vizinhança pode compensar as carências ambientais, diante da construção de vínculos e amizades (MOSER, 2018).

Nesse contexto, é importante ressaltar, também, o lar como lugar onde afloram diversos elementos da Psicologia Ambiental, entre eles o sentimento de conforto e de segurança. Além dessas funções psicológicas, muitas outras são atribuídas ao lar, variando de acordo com o tipo de laço afetivo existente, a experiência pessoal e o contexto cultural (GIULIANI, 2004).

O foco dos espaços residenciais é a satisfação plena dos seus moradores e para isso precisam entrelaçar aspectos funcionais e estéticos, respeitando-se os princípios da ergonomia e utilizando-se conceitos da Psicologia Ambiental, reforçando, ainda mais a intensidade das relações pessoaambiente nos lugares significativos para suas vidas e a importância dessas relações para a saúde psíquica das pessoas.

Segundo Bins Ely (2003 apud VASCONCELOS; VILLAROUCO; SOARES, 2010), a arquitetura pode associar-se ao conhecimento de Ergonomia para criar ambientes atrativos e funcionais durante 0 exercício projetual. Dessa forma, as sensações provocadas pelo ambiente através das suas 


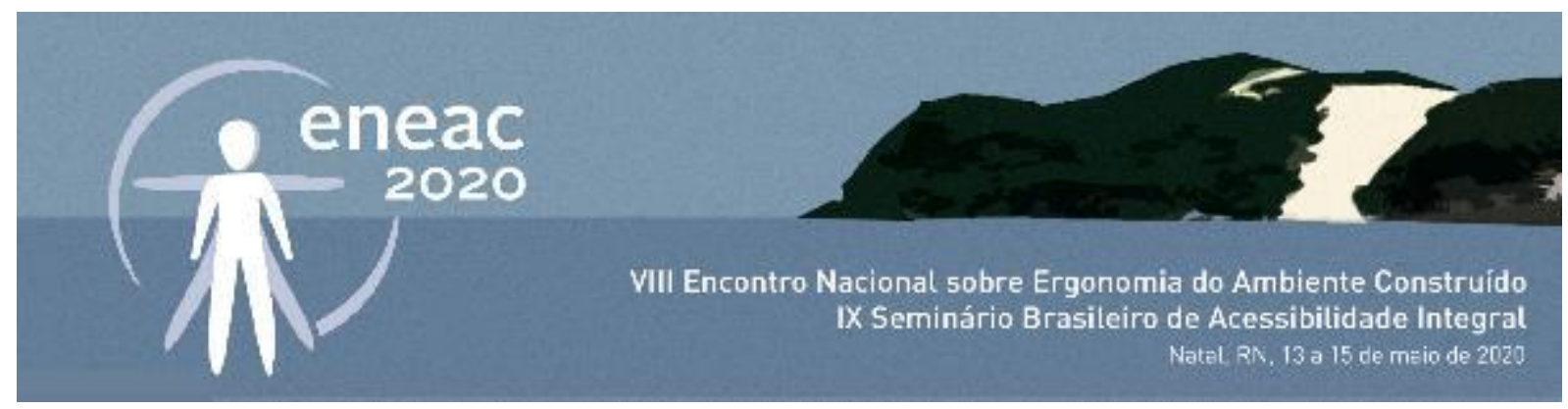

necessidades estéticas ou formais também influenciam nas preferências dos indivíduos, conforme sua história de vida pessoal e seu contexto sociocultural.

Elali (1997 apud VASCONCELOS; VILLAROUCO; SOARES, 2010) defende que o edifício não deve ser analisado somente considerando suas características físicas, mas também focando sua condição "vivencial", sujeito à ocupação, leitura, reinterpretação e modificação pelos usuários, observando as questões comportamentais ocorridas nele.

Vários aspectos devem ser considerados, então, ao se projetar um ambiente residencial, tanto externo quanto interno, como: iluminação, cores, ventilação, presença de plantas, entre outros. Esses elementos influenciam tanto na saúde quanto na produtividade dos indivíduos, além de facilitarem o estabelecimento de relações entre as pessoas e os espaços, sendo de suma relevância a correta utilização destes ambientes (RIBEIRO, 2005).

O conjunto desses elementos, quando utilizados de maneira equilibrada e bem projetada, tende a facilitar o alcance da satisfação do usuário, atendendo às suas necessidades e expectativas, além de possibilitar a vivência de novas experiências de relacionamento com o ambiente construído (ver figura 1). Esses aspectos são válidos para todos os tipos de espaços projetados, sejam eles residenciais, corporativos ou educativos.

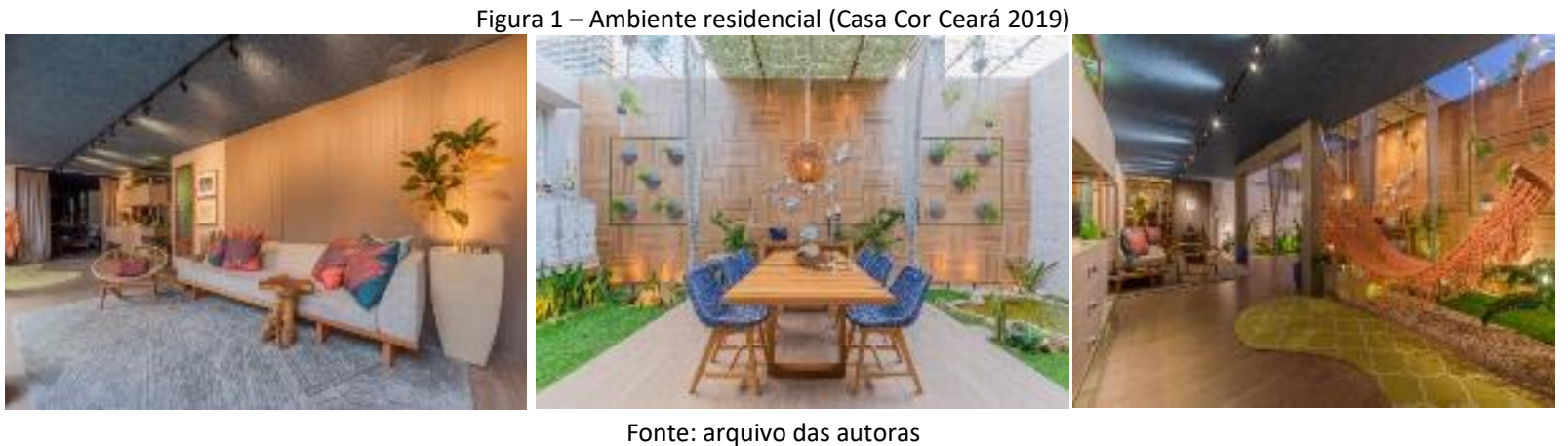

\subsection{A Psicologia Ambiental e a Ergonomia nos Espaços Corporativos}

A congruência existente nas relações entre pessoas e ambiente não está contida apenas no ambiente residencial, mas também nos espaços de trabalho, estudo ou institucionais, os quais devem atender às necessidades dos ocupantes. É, portanto, após a ocupação dos espaços que se pode observar a inadequação dos projetos devido à falta de importância dada às exigências dos frequentadores, causando, assim, extrema insatisfação dos usuários e, consequente, queda na produtividade (MOSER, 2018).

Alguns estudos referentes à Psicologia Ambiental nos ambientes corporativos projetados contribuem, portanto, para a concepção de espaços de trabalho que facilitem o desempenho das empresas, além da satisfação, segurança, equilíbrio e bem-estar dos seus usuários (RIBEIRO, 2005).

Um ambiente corporativo pode estimular comportamentos diversos na rotina de um trabalhador, onde um conjunto de ações podem modificar o desempenho de suas atividades. Silva (2001, apud VILLAROUCO; ANDRETO, 2008) descreve que os aspectos ligados ao conforto ambiental tais como ruído, iluminação, temperatura, umidade e pureza do ar, radiação, esforço físico, tipo de vestimenta, etc., são elementos preponderantes no bem-estar dos trabalhadores e na qualidade dos serviços. 


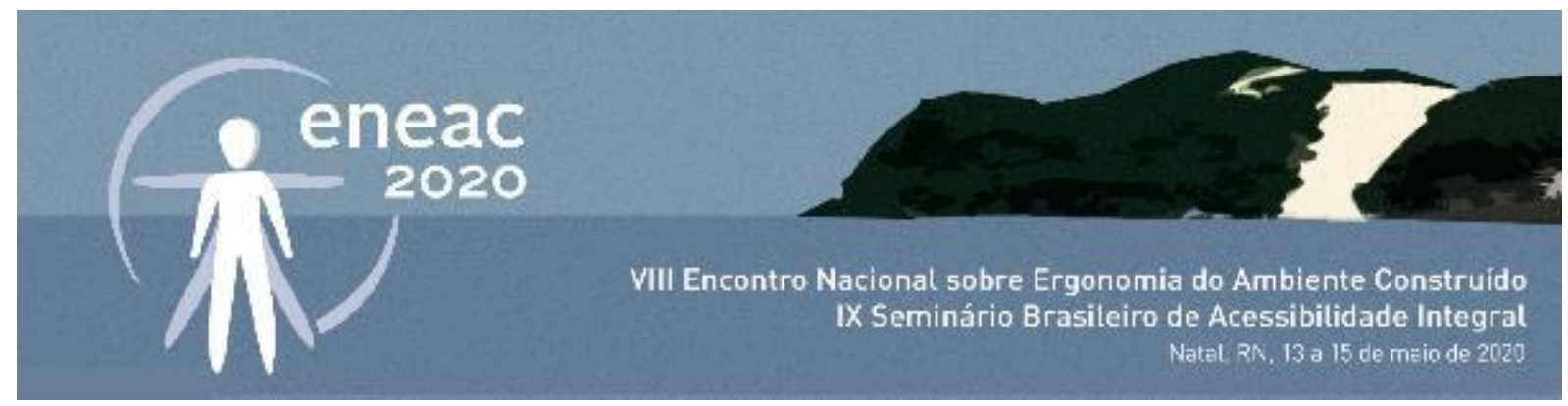

Afirma ainda que existem estudos mostrando aumento de produtividade quando os sistemas de iluminação e climatização são controlados pelos próprios trabalhadores. Nessas observações constatou-se que a temperatura elevada em espaços corporativos gera cansaço e sonolência reduzindo a eficácia e eficiência no serviço.

Villarouco e Andreto (2008) também citam um estudo descrito por Hall (1977) e realizado por J. W. Black onde foi avaliado que o tamanho e o tempo de reverberação de um cômodo influenciam nos índices de leitura. Segundo essa pesquisa, os indivíduos tem uma leitura mais lenta em ambientes de maior área, onde o tempo de reverberação é maior, diferentemente de ambientes menores. Dessa forma, o dimensionamento e condição acústica dos espaços seriam elementos de grande preocupação em ambientes educacionais e corporativos.

Ainda segundo Villarouco e Andreto (2008, p: 524) a Psicologia Ambiental e a Ergonomia são duas disciplinas que tem fundamental importância na qualidade de uso de espaços corporativos. Os autores descrevem que:

\begin{abstract}
A Psicologia Ambiental revela a importância dos fatores físicos e simbólicos dos espaços de trabalho e a relação desses com os indivíduos. A Ergonomia preocupa-se com os objetos que compõem o ambiente de trabalho e sua relação com a funcionalidade, o significado e o componente social, além de estudar a maneira como os espaços são utilizados, buscando uma adequação do processo produtivo, por meio de uma configuração espacial que reflita as exigências do trabalho, favoreça a saúde, a segurança e a produtividade.( VILLAROUCO; ANDRETO, 2008, p: 524)
\end{abstract}

Assim, é de grande relevância para os ambientes comerciais e corporativos a utilização dos conceitos da Psicologia Ambiental nos seus espaços, visto que esses podem ser geradores de sentimentos de satisfação naqueles que os frequentam, proporcionando, dessa forma, resultados positivos para as empresas em relação ao relacionamento com seus usuários. Na figura 2 observa-se um projeto de escritório com aplicação de conceitos de Ergonomia e Psicologia Ambiental.

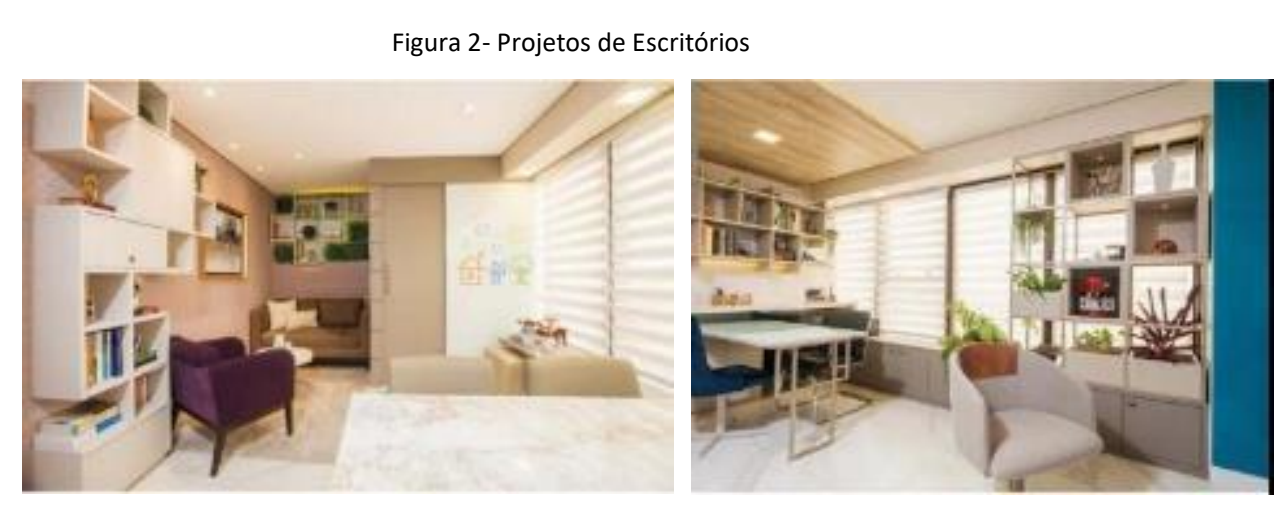

Fonte: acervo das autoras

\title{
3.3 A Psicologia Ambiental e a Ergonomia nos Espaços Educativos
}

Segundo Bernardes e Vergara (2017), os espaços escolares projetados com a aplicação da Psicologia Ambiental e aspectos restauradores influenciam positivamente no aprendizado e no desenvolvimento das crianças. Essas características englobam principalmente a fascinação, 


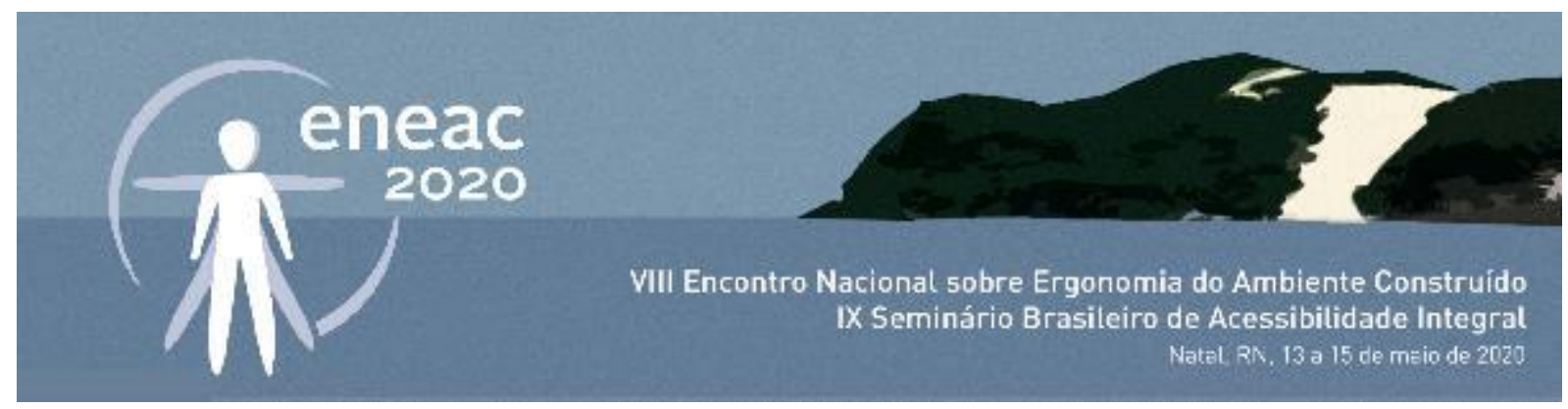

contemplação, sensação de liberdade e conexão com a paisagem, sendo estas mais facilmente encontradas nos ambientes naturais, os quais favorecem, também, uma vida mais saudável aos seus usuários como se observa na figura 3.

A escola é uma importante referência na vida das pessoas desde a infância, pois neste local sentemse protegidas e costumam apropriar-se com mais intensidade dos espaços de convivência, como o pátio, a quadra de esportes e o refeitório. $O$ desenho dos ambientes escolares quando possuem um caráter humanizador e ergonômico, promovem uma diversidade de usos, facilitam o processo pedagógico e empoderam seus usuários. A aplicação correta da Ergonomia nos espaços administrativos da escola contribui de forma positiva na produtividade e na concentração dos funcionários, além de evitar afastamentos por adoecimentos.

A estratégia de proporcionar espaços recreativos com maior presença de vegetação e elementos naturais, tem evoluído nas últimas décadas, onde os profissionais buscam associar conhecimentos de Psicologia Ambiental, Arquitetura, Ergonomia e Paisagismo nos projetos. Os alunos através do contato direto com a natureza, desenvolvem a liberdade e autonomia para realizar ações do brincar e aprender.

Sager et al (2003) apud Oliveira e Gonçalves (2019) descrevem que os espaços deveriam ser organizados considerando as referências do local e a integração de seus respectivos agentes. Os alunos devem participar desse processo visando a sua identificação com os ambientes que ocupam, gerando um sentimento de pertencimento e apropriação, que é uma questão bastante relevante na Psicologia Ambiental (ver figura 3). Os comportamentos dos alunos costumam modificar-se dependendo do dimensionamento dos espaços, sendo os ambientes os maiores facilitadores das interações entre eles. As autoras também concordam com o pensamento de Pol (1996) que ressalta essa apropriação do espaço condicionada por dois fatores: o psicológico e o pedagógico, sendo que o primeiro reforça a autoimagem frente a si e o pedagógico desenvolve os aspectos sociais e comunitários a partir da criatividade.

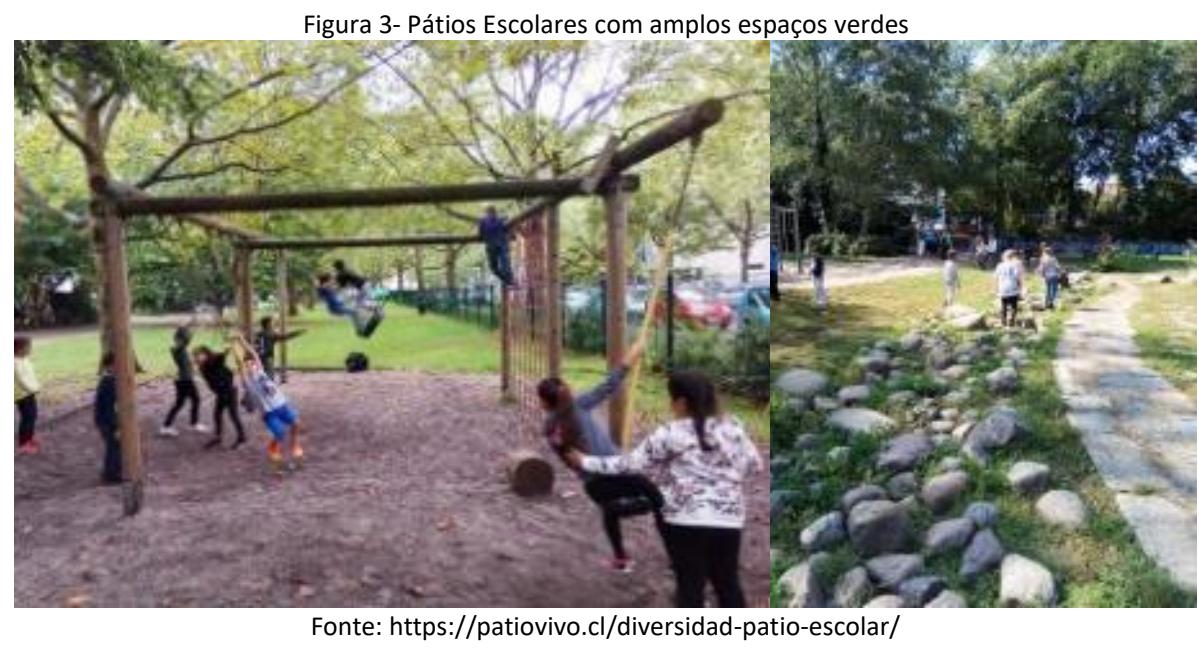

Dessa forma, a arquitetura escolar pode ser beneficiada pela aplicação da Psicologia Ambiental, estabelecendo uma conexão direta entre o edifício principal, os pátios jardins (espaços ao ar livre) e 


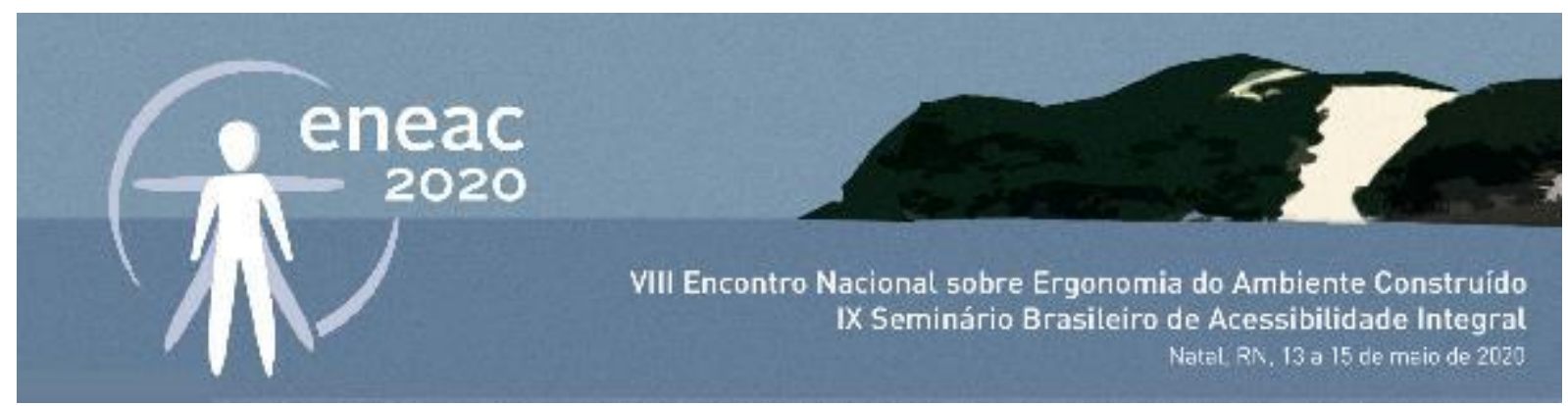

os pátios cobertos, que podem ser considerados como uma extensão das salas de aula. Esses espaços também funcionam como locais de aprendizagem, sendo ambientes que aumentam as áreas de sombra, promovem a permeabilidade do solo, permitem maior incidência de luz e ventilação gerando maior conforto visual e térmico. Essa prática projetual consegue assim aplicar uma pedagogia positiva na materialidade do espaço.

\section{CONSIDERAÇÕES FINAIS}

Percebeu-se, ao longo desse estudo, que o bem-estar das pessoas que habitam, usufruem ou frequentam um espaço projetado está diretamente ligado aos elementos da Psicologia Ambiental presentes nesse ambiente. A Psicologia Ambiental, juntamente com a Ergonomia desenvolve nos usuários dos ambientes, sensação de agradabilidade, contemplação e conforto físico, aspectos facilmente vivenciados em ambientes projetados, sejam eles residenciais, corporativos, educacionais ou públicos, por meio de vários elementos, entre eles a contemplação da natureza, a iluminação adequada, dimensionamento correto de mobiliários, áreas de circulação, além do conceito de ambientes restauradores, proporcionando maior bem-estar e qualidade de vida às pessoas.

De maneira especial, o conceito de ambiente restaurador tem-se destacado nos ambientes projetados, devido a sua influência na saúde física e psíquica dos seus usuários, tendo sido bastante explorado nos projetos mais recentes. Os ambientes projetados com o uso de elementos restauradores, tem alcançado maior satisfação e bem-estar de seus usuários, tanto nos espaços residenciais, como corporativos, escolares e públicos, demonstrando, assim, a importância da aplicação desse conceito nos projetos em geral. Assim, o uso de elementos da Psicologia Ambiental associado aos benefícios da Ergonomia, potencializam as interações pessoa-ambiente e, consequentemente, o aumento do bem-estar e da qualidade de vida da sociedade.

Esses fatores vêm evidenciar claramente a relevância desta pesquisa, a qual demonstrou a necessidade das interrelações pessoa-ambiente e a possibilidade de vivenciá-las com mais facilidade nos ambientes projetados com base em conceitos da Psicologia Ambiental e da Ergonomia. Sabe-se, porém, que muito ainda se tem a descobrir sobre essas relações e espera-se ter contribuído positivamente com o assunto abordado, despertando, dessa forma, outras pesquisas voltadas para o referido tema.

\section{REFERÊNCIAS}

BERNARDES, M.; VERGARA, L. G. L.; Aprendiendo entre la naturaliza: uma revisión de los benefícios de los espacios verdes em el ambiente escolar. Arquitecturas del Sur, 35(52), 2017. pp.96-103.

BERTINI, F. M. A. Centro de Fortaleza, lugar de transformações: o idoso e os afetos implicados. Dissertação de mestrado não publicada, Universidade Federal do Ceará, Fortaleza, 2006.

BERTO, R. The role of nature in coping with psycho-physiological stress: a literature review on restorativeness. Behavioral Sciences, 4, 2014. pp. 394-409. Disponível em: https://doi.org/10.3390/bs4040394. Acesso em 8 out. 2019.

CARVAlho, M. I. C.; CAVAlCANTE, S; NÓBRegA, L. M. A. “Ambiente”. In: CAVAlCANTE, S.; Elali, G. A. (Orgs.), Temas básicos em psicologia ambiental. Petrópolis: Vozes, 2011. pp.28-43.

CAVALCANTE, S.; NÓBREGA, L. M. A. “Espaço e Lugar”. In: CAVALCANTE, S.; ELALI, G. A. (Orgs.). Temas básicos em psicologia Ambiental. Petrópolis: Vozes, 2011. pp. 182-190. 


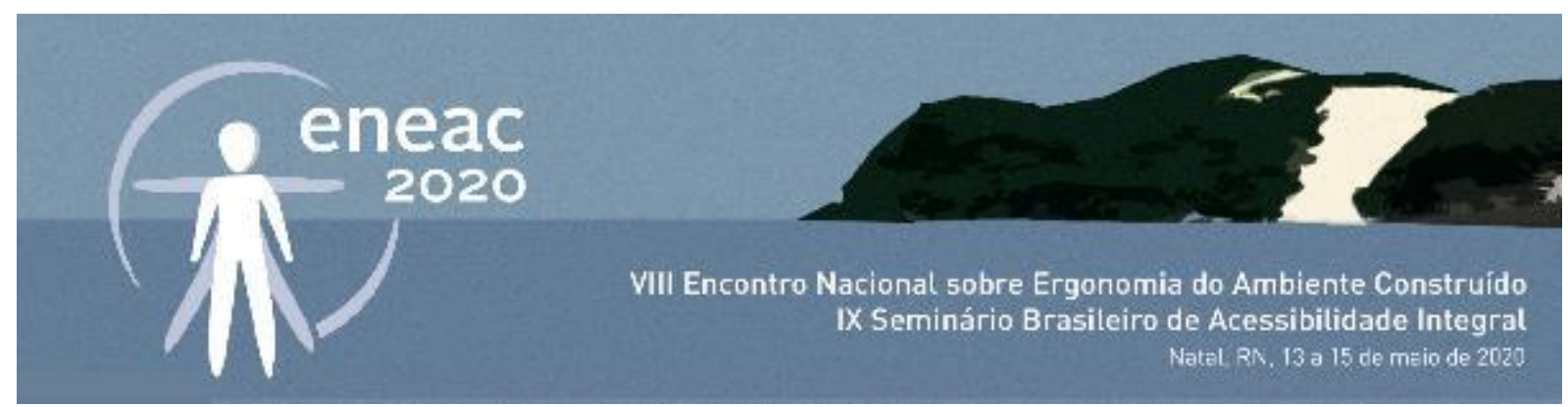

ELALI, G. A. "Relações entre comportamento humano e ambiência: Uma reflexão com base na psicologia ambiental". In: Anais do colóquio ambiências compartilhadas, 2009. p.1-14.

FALAVIGNA, R. F.; BAVARESCO, A. M. A Psicologia do Espaço Construído. Anuário Pesquisa e Extensão UNOESC- São Miguel do Oeste 2018

FELIPPE, M. L.; KUHNEN, A. "O apego ao lugar no contexto dos estudos pessoa-ambiente: Práticas de pesquisa”. In: Estudos de psicologia: 29 (4), 2012. p.609-617.

FRANCISCO, T. M. S.; FOLLMANN, J. I.; GIOVANNI, E. N.; GONÇALVES, T. M.“A praça, a poética e os processos de identidade: desvelando aspectos da identidade urbana". In: Revista Ra'e Ga: 31, 2014. p. 91-116. Disponível em:

https://revistas.ufpr.br/raega/article/view/30406/23013. Acesso em 12 set. 2019.

GIFFORD, R. Environmental Psychology Matters. Annual Review of Psychology, 65, 2014. p.541-579. Disponível em: https://doi.org/10.1146/annurev-psych-010213-115048. Acesso em 7 out. 2019.

GIULIANI, M. V. "O lugar do apego nas relações pessoas-ambiente”. In: TASSARA, E. T. D O.; RABINOVICH, E. P.; GUEDES, M. DO C.(eds.). Psicologia e ambiente. São Paulo: Educ, 2004. p. 89-106.

IIDA, Itiro. Ergonomia: projeto e produção. 2ª ed. São Paulo: Blucher, 2005.

KUHN, E.; BARBOSA, C. Relação entre ergonomia e qualidade de vida no trabalho. Brazilian Journal of Surgery and Clinical Research. 14(3), 2016. p.87-90.

KUHNEN, A. Representações sociais de meio ambiente: estudo das transformações, apropriações e modos de vida na Lagoa da Conceição-Florianópolis/SC, 2001.

LEITE, J. "O espaço da arquitetura e do urbanismo: uma componente sensível na compreensão das relações sociais da pósmodernidade". In: Comunicação e Sociedade: 18, 2010. p. 149-156.

LIMA, D. M. A.; BOMFIM, Z. A. C. "Vinculação afetiva pessoa-ambiente: Diálogos na psicologia comunitária e psicologia ambiental". In: Psico - PUC-RS: 40(4), 2009. p. 491-497. Disponível em: http://revistaseletronicas.pucrs.br/ojs/index.php/ revistapsico/article/view/4711. Acesso em 7 out. 2019.

MORAIS, T. N.; ARAÚJO, D. S. da R.; BARBORA, J. M.; ABREU, F. W. S.; SIEBRA, L. M. G. Nas Trilhas da Psicologia Ambiental. Extensão Em Ação - XIX Encontro de Extensão Universitária Meio Ambiente, 2011. 1(1), 51-58. Retrieved from http://www.repositorio.ufc.br/bitstream/riufc/13252/1/2011_art_tnmorais.pdf. Acesso em 22 out. 2019.

MOLAVI, M.; SEYEDABADI, M.; ZALI, N. "Investigating the Significance of Physical and Functional Factors in the Vitality of Urban Squares (The Case of Sabzemeydan Square, Rasht)". In: Anuário do Instituto de Geociências - UFRJ: 40(2), 2017. ps. 199-209. Retrieved from http://www.anuario.igeo.ufrj.br/2017_2/2017_2_199_209.pdf. Acesso em 22 out. 2019.

MOSER, G. "Espaços urbanos e convivência”. In MOSER, G. Introdução à psicologia ambiental: Pessoa \& ambiente. Campinas: Alínea, 2018. p. 181-215.

“Os espaços privados". In: MOSER, G. Introdução à psicologia ambiental: Pessoa \& ambiente. Campinas: Alínea, 2018. p. 87-101

"Territórios partilhados e espaços semipúblicos". In: MOSER, G. Introdução à psicologia ambiental: Pessoa \& ambiente. Campinas: Alínea, 2018. p. 103-127.

OLIVEIRA, Roselene V.; GONÇALVES, Teresinha M. O Espaço sociofísico da escola como facilitador das relações no ambiente escolar:um estudo de psicologia ambiental. Revista Tecnologia e Ambiente, v.25, 2019, Criciuma, Santa Catarina/SC

PONTE, A. Q.; BOMFIM, Z. A. C.; PASCUAL, J. G. “Considerações teóricas sobre identidade de lugar à luz da abordagem histórico-cultural. In: Psicologia Argumento: 27(59), 2009, p. 345-354.

RAIMUNDO, S.; SARTI, A. C. (2016). Parques urbanos e seu papel no ambiente, no turismo e no lazer da cidade. RITURRevista Iberoamericana de Turismo, 6(2), 2016. p 3-24. 


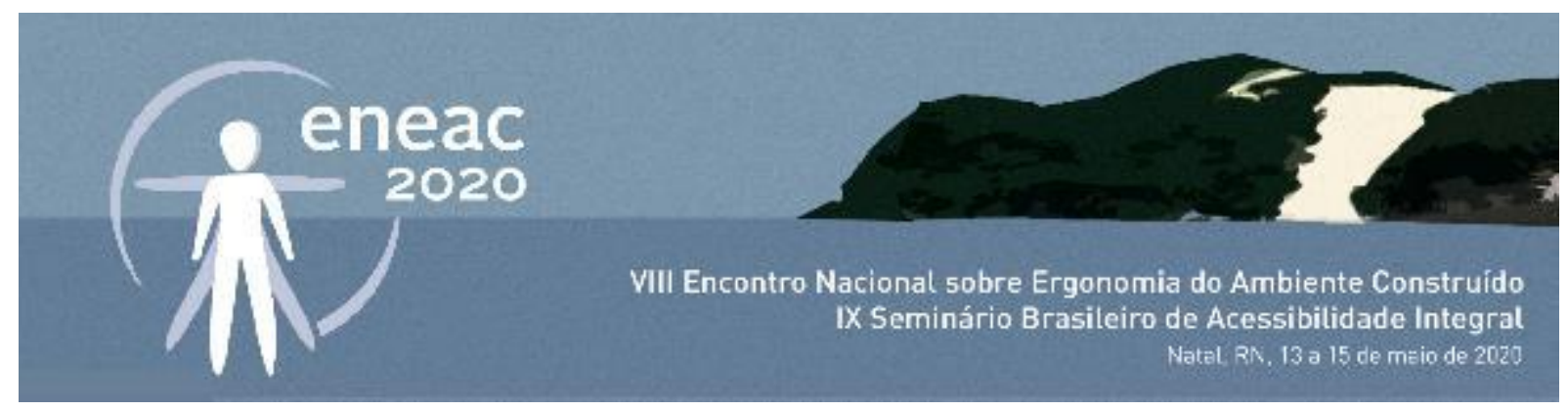

RIBEIRO, T. "Ambientes laborais: espaços de trabalho em contexto organizacional”. In: SOCZKA, L. (Org.). Contextos humanos e psicologia ambiental. Lisboa: Fundação Calouste Gulbonkian, 2005. p. 337-379.

SIEBRA, L. M. G.; BOMFIM, Z. A. C.; SOUSA, L. C. A.; OLIVEIRA, M. F.; SOARES, M. R. "Metodologias de investigação-ação em psicologia ambiental". Extensão Em Ação: 1(8), 2015. p. 42-55.

THIBAUD, J. "Ambiência”. In: CAVALCANTE, S.; ELALI, G. (Orgs.). Psicologia Ambiental: conceitos para a leitura da relação pessoa-ambiente. Petrópolis: Vozes, 2018. p. 13-25.

VASCONCELOS, C. F.;VILLAROUCO, V.; SOARES, M. M. Contribuição da Psicologia Ambiental na Análise ergonômica do ambiente Construido. Ação ergonômica, volume 5, número 3. Dez/2010

VILLAROUCO, V.; ANDRETO, L. F. M. Avaliando desempenho de espaços de trabalho sob o enfoque da ergonomia do ambiente construído- Prod. vol.18 no.3. São Paulo Sept./Dec. 2008 